\title{
High-Speed Railway and Regional Economic Growth: An Empirical Study Based on Market Potential
}

\author{
Qingyi Shi \\ School of Economics, Jinan University, Guangzhou, China \\ Email: shiqingyi907@163.com
}

How to cite this paper: Shi, Q.Y. (2018) High-Speed Railway and Regional Economic Growth: An Empirical Study Based on Market Potential. American Journal of Industrial and Business Management, 8, 83-102. https://doi.org/10.4236/ajibm.2018.81006

Received: December 19, 2017

Accepted: January 16, 2018

Published: January 19, 2018

Copyright $\odot 2018$ by author and Scientific Research Publishing Inc. This work is licensed under the Creative Commons Attribution International License (CC BY 4.0).

http://creativecommons.org/licenses/by/4.0/

\section{(c) (i) Open Access}

\begin{abstract}
This paper presents empirical work in investigating the effect of high-speed railway's impact on regional economic growth. The study selects the major cities nationwide as its research objects and introduces market potential indicator which varies with the reduction of railway travel time. The total sample estimation's result proves that HSR's effect on per capital GDP is negative, but it has a positive impact on the population. When the samples are grouped to estimate, it proves that the development of high-speed rail is conducive to the further rise of big cities, but not to the development of small and mediumsized cities. For the areas where HSR connects to a network, HSR compresses space and time and promotes the cooperation or communication among cities. For the areas where HSR is relatively backward, HSR increases its marginalization, resulting in a negative impact. Therefore, it is believed that the development of China's HSR should pay attention to rational distribution, give more consideration to backward areas, and promote the coordinated development of the region.
\end{abstract}

\section{Keywords}

High-Speed Railway, Economic Effects, Instrumental Variables

\section{Research Background}

Due to the unbalanced spatial distribution of resources and economic development, there is a great demand for cross-regional mobility of personnel and materials in China. On the other hand, China's land area is too large, so that the railway transport capacity cannot meet the national economic development for a long time. This problem is especially obvious during the Spring Festival or other 
holidays. The concentrated passenger flow makes the transport capacity more restricted. In recent years, the urban agglomeration constantly springs up in China with the rapid development of urbanization. As a result, higher requirements for the carrying capacity of transportation infrastructure are raised because of the growth in passenger transport demand among central cities and within the urban agglomeration. The high-speed railway is characterized by high speed, large carrying capacity and extensive coverage, which can meet the passenger transport demands of large capacity, high density, efficiency and convenience. Therefore, the high-speed railway has been prosperously constructed in China recently. By the end of 2015, 71 high-speed railway lines in operation have been established in China with a total length of 23,600 km, ranking the first in the world. Meanwhile, China is perfecting its "four vertical and four horizontal" high-speed railway network, and supporting the construction of high-speed railway extension, so as to form an accessible, convenient and powerful network with wide coverage.

Playing an important role in China's transportation system, high-speed railway has deepened its regional impact and exerted direct or indirect economic effect on the cities along it. It is generally believed that high-speed railway can: 1) affect regional accessibility; 2) enhance inter-regional economic ties; 3) accelerate the social resource flow; 4) achieve the spatial agglomeration and re-allocation of economic activities, thus promoting the regional economic growth [1]. However, there is no sufficient evidence to prove such viewpoint. While we have also noticed that the nationwide construction and the continuous increase in construction investment have caused a huge burden on the national economy. In addition, the high-speed rail station is often located in core cities, and the stop frequency is based on cities' level and strength, which may lead to the accessibility enhancement in major cities and marginalization of small cities.

Aiming to explore the economic growth effect of high-speed railway, this paper will establish market potential indicators to test the impact on regional economic growth caused by market potential improvement arising from high-speed railway development. Market potential is a concept used by economic geographers to measure a specific geographic area's access to market for inputs and outputs. The economic geography model of MP posits that those geographic areas with greater access to markets will be richer [2] [3] [4]. The introduction of the HSR increases market potential and thus, market integration, the most for the secondary cities is close to the megacities and also enhances spatial agglomeration. We document a robust correlation between city growth in market potential and city growth in RGDP or population [5].

This research can be divided into seven parts: the second part is literature review; the third part analyzes the influencing mechanism of high-speed railway on the economy; the fourth part introduces the research methods of this paper, including model setting and data processing; the fifth part discusses the empirical results; the sixth part is about sample selection and endogenous issues; the 
seventh part summarizes the economic effects brought by the high-speed railway development in China, and puts forward some proposals for its development.

\section{Literature Review}

Transportation is a major part of economic activities, so many economists have paid their attention to its connection with economic growth. And the railway's role in economic growth has always been controversial. Some traditional economists stress that the railway has an unprecedented maximum capacity and has a great impact on all aspects of the economy. They attributes the impact of railways on economic growth to reducing transportation costs and expanding markets and stimulating the development of modern industries, such as coal mining, cast iron and machinery [6].

However, some economists believe that the railway is not so important. The most famous one is Fogel (1964). In his Railway and Economic Growth in America, he uses the "social saving" to represent the economic benefits of transportation. Then he applies the anti-factual measure. Specifically, he assumes that there is no railway in America, and the economic benefit can be only obtained from the river/canal transportation. Contrasted with the economic benefit brought by railway transportation, he finds that the difference of their impact on GNP growth is quite modest. That is to say, railways are not essential in economic growth, because it can be replaced by water transportation [7]. Some scholars are skeptical about Fogel's theory. Through the establishment of market access indicators and the application of anti-factual research and social saving, Donaldson (2016) has also tested the railways' impact on the economy in America from 1870 to 1890 . The results show that the railway has greatly increased the value of agricultural land, and its status was irreplaceable [8].

The rapid progress and extensive construction of high-speed railway technology have triggered a new round of international discussion on the economic impact of high-speed railway. Vickerman (1997) has studied the impact of highspeed railway construction on regional development in Europe, showing that the high-speed railway can benefit metropolis. Because all major elements will be gathered in metropolis, thus improving the concentration of major central cities [9]. Schade (2006) believes that the high-speed railway is in favour of strengthening the ties between the marginal and the central areas in Europe. But the gap between them ("center-margin") will also be enlarged [10]. Monzón (2013) uses the GIS technology to research the impact of high-speed railway on the city's efficiency and fairness in Spain, showing that the high-speed railway can significantly improve cities' accessibility [11]. But the spatial imbalance will be intensified while enhancing the regional advantages and attractiveness. Through research, Kim (2015) finds that the high-speed railway has different impacts on the region at each development stage in South Korea. Specifically, in the early and mid-term, the high-speed railway may cause the unbalanced accessibility and regional development because of the efficiency problem. While the accessi- 
bility of isolated areas will be enhanced latterly [12], Hall (2011) believes that the regional impact of high-speed railway on economic geography in the UK can be divided into 1-hour zone, 2-hour zone and above-2-hour zone, among which the regional economic growth in the 2-hour zone will be substantially and greatly impacted. Besides, the city with high-speed railways can better grasp the development opportunity compared with the city without high-speed railways [13]. Takuma et al. (2016) have studied the impact of Japanese shinkansen on economic productivity, finding that the accessibility has a significant positive impact on economic productivity, that is, the region with high-speed rail station has a higher productivity. What's more, the high-speed railway will contribute to narrowing the productivity gap between outer and central cities [14]. Albalate (2016) has used the difference-in-difference method to assess the contribution of high-speed railway to the tourism growth in Spain. On one hand, the high-speed railway has an impact on air transportation which indicates the tourist amount, thus indirectly impacting the tourist industry. On the other hand, the high-speed railway has a weak positive impact on tourist amount. Whether its net effect on tourist economy is positive depends on the technology used to calculate the accessibility and economy [15].

Our domestic scholars also passionate about researching the economic effect brought by high-speed railway. Zhao Qingguo (2013) believes that the high carrying capacity of high-speed railway can provide efficient transport support for economic development. The space-time compression will help to form a unified regional market. And meanwhile, the radiation effect will create economic corridors or economic belts along the railway [16]. Qin Chenglin and Chong Zhaohui (2014) have analyzed the impact of high-speed railway on urban economy agglomeration, finding that the $1 \%$ increase in urban accessibility will increase the economy agglomeration index by 0.8 [17]. Wang Jianfeng and $\mathrm{Li}$ Zhigang et al. (2014) has used the "with and without comparison method" in their research. The results show that Shanghai-Hangzhou high-speed railway has a positive impact on the economic development of Zhejiang province. But the effect will vary with place and time, thus having no universality [18]. Song Wenjie et al. (2015) have analyzed the impact of high-speed railway from three aspects of accessibility improvement, development situation around high-speed rail station and urban economic development. It is believed that: 1) the tertiary industry will experience a spatial polarization in metropolis with the impact of high-speed railway; 2) the metropolis and small-medium cities will make a cooperation in the secondary industry; 3 ) the small-medium cities will obtain the positive diffusion effects [19]. Wang Yufei and Ni Pengfei (2016) have used the spatial econometric model in their research. The results show that the development of high-speed railways is not only beneficial to the economic spillover effect among regions, but also changes the economic spatial pattern [20]. There are also many scholars taking the Wuhan-Guangzhou high speed rail as the object of research, they find it has significant transportation and nontransportation 
impacts on the cities and megaregions along the line. However, it still has generated geographic and social inequity issues yet to be addressed [21] [22].

Through reviewing the existing researches, some conclusions can be obtained. From the perspective of research method, it is found that these existing researches only use the situation analysis to assess the situation with/without highspeed railways, or simply calculate and compare the accessibility to make a qualitative description towards the changes brought by high-speed railways. That is to say, there are comparatively fewer empirical researches. From the research perspective, most of the current researches only focus on the positive promotion of high-speed railway on industries, regions and cities, thus neglecting its different impacts at different economic development stages and the problem of regional fairness. From the perspective of research object, there are two problems: 1) these researches often take eastern and central cities as the example, and the western cities are rarely mentioned; 2) these researches only center on the single high-speed rail line or province, that is, they fail to consider the entire highspeed railway network as a whole.

In this paper, a quantitative empirical method is used to compare the different impacts of high-speed railways on economic growth in accordance with time and place. On one hand, it analyzes the overall effect on economic growth in metropolis based on the entire high-speed railway network. On the other hand, it compares the different effects brought to the eastern and western cities due to the unbalanced construction of high-speed railway network. Meanwhile, it also compares the marginal utility of high-speed railway at different economic development stages. In addition, this paper considers the endogeneity problem. With the introduction of instrumental variables, the relationship between the high-speed railway and economic growth can be rigorously proved.

\section{Research Method and Data}

\subsection{Research Methodology}

The high-speed railway has reduced the travel time between cities, thus facilitating the trade flows among cities, market expansion and knowledge spillover sharing. The demand for goods and services in one city is the sum of purchasing power of its neighboring cities. Therefore, BT is defined as the space-time weighted purchasing power of neighboring cities. It is known as the market potential, which has been explained in the research background. BT of $i$ city in the year of $\mathrm{t}$ can be represented by the formula below:

$$
B T_{i, t}=\sum_{j=1}^{n} \frac{G D P_{j, t}}{T_{i j, t}}(i \neq j)
$$

There into, $G D P_{j, t}$ stands for the gross regional production of $j$ city in the year of $t$. $T_{i, j}$ stands for the travel time between $i$ city and $j$ city in the year of $t$ (minute-based).

In order to estimate the impact of high-speed railways on regional economic 
growth, this paper takes two periods as the model-one is the year of 2000, during which the high-speed railway is not available; the other is the year of 2013, during which the high-speed railway is available.

The reasons for the choice of time period are as bellow. The definition of the high-speed railway by the National Railway Administration is as follows: new designed and operated D-series high-speed trains with a speed of $250 \mathrm{~km} / \mathrm{h}$ (including reservation), and the passenger dedicated lines with an initial speed of not less than $200 \mathrm{~km} / \mathrm{h}$. Qin-Shen Passenger Railway, which is operated in 2001 with the running speed of $200 \mathrm{~km} / \mathrm{h}$ and the infrastructure reservation of 250 $\mathrm{km} / \mathrm{h}$, ushers in the era of high-speed railway in China. Qin-Shen Passenger Dedicated Line belongs to high-speed train, so this paper selects the year of 2000 as the stage before introducing the high-speed railway. Due to our research group has collected the 2013 train operation time, and it is the latest data available when writing the paper, so we choose 2013 as the current year.

The basic model form is as follow:

$$
\Delta_{2000-2013} \ln Y_{i}=\beta_{0}+\beta_{1} \cdot \Delta_{2000-2013} \ln \left(B T_{i}\right)+\varepsilon_{i}
$$

There into, $Y_{\mathrm{i}}$ stands for the per capita gross regional production (RGDP) or population (POP) of $i$ city $^{1} . B T_{i}$ stands for the market potential of $i$ city. $\Delta 2000-2013$ stands for the logarithmic change of the variables between 2000 and 2013, that is, the difference between the logarithm of 2013 and the logarithm of 2000.

For this model, the right side of the equation only refers to the development of the railway between 2000 and 2013. While there are still many factors that affect economic growth. In order to accurately measure the impact brought by high-speed railway, this paper adds control variables to control other factors affecting the economic growth based on the basic model. With $X_{i, t}$ to represent the control variables, the extended model is as follow:

$$
\Delta_{2000-2013} \ln Y_{i}=\beta_{0}+\beta_{1} \cdot \Delta_{2000-2013} \ln \left(B T_{i}\right)+\gamma \Delta_{2000-2013} \ln X_{i}+\varepsilon_{i}
$$

There into, $Y_{i}$ and $B T_{i}$ are consistent with those in the basic model. $X_{i}$ stands for control variables, including the capital, labor, education (edu), infrastructure (infras), other transportation (trans) and industrial structure (industry), etc. $\Delta 2000$-2013 also stand for the logarithmic change of the variables between 2000 and 2013.

Capital and labor represent the basic factor inputs. Considering that the error may be caused by perpetual inventory method, the proportion of fixed asset investment in gross regional production is regarded as the proxy variable of capital, and the proportion of employees in the total population is regarded as the proxy variable of labor. Considering that the impact of science and education

${ }^{1}$ In general, the growth rate of population is positively correlated with the level of economic development. On one hand, this paper directly reflects the level of urban economic growth with the RGDP. On the other hand, it also indirectly measures the level of urban economic development by the urban population [23]. 
level on economic development, the proportion of science and education expenditure in the total public financial expenditure is regarded as the proxy variable of edu. Considering that urban infrastructure can affect the development prospect, the road area per capita is added to represent infras.

In addition, the impact of other transport facilities is also taken into account. Considering that the freight capacity can better measure the economic development level compared with the passenger capacity, the total freight capacity of highway, shipping, water transport and railway is taken as the variable representing trans. This paper aims to explore the impact of the development of high-speed railways. However, the reduction of travel time in 2013 compared with that in 2000 is caused by the introduction of high-speed railways and the speed-up of ordinary railways. Therefore, it is necessary to add the control variable that represents ordinary railways. This paper selects the railway freight volume as the proxy variable of the development of ordinary railways. Because high-speed railways in China are basically passenger dedicated lines, and the special freight high-speed trains for freight transport have been developed. In other words, the high-speed railway has not yet achieved freight transport so far, and the freight transport still depends on ordinary railways. For other transportation modes, this control variable includes not only the freight capacity of railways, but also the freight capacity of highways, waterways and airways, thus controlling the impact brought by the development of ordinary railways, and the impacts brought by the development of highways, airways and waterways.

Finally, considering the close relationship between the industrial structure and economic development level, the proportion of secondary industry's production value in the gross regional production is regarded as the proxy variable of industry.

\subsection{Data Sources}

Focusing on the impact of high-speed railways on the regional economy, this paper selects the major cities nationwide as its research objects. The 36 capital cities and specifically-designed cities cover all provinces in China and represent the development level of each region. The reason why to select these cities is that their statistical data are more complete. However, Lhasa and Haikou have no railways in the base period of 2000, so they are excluded, and the other 34 cities are reserved.

The data mainly come from the China City Statistical Yearbook and China Regional Economic Statistical Yearbook published in 2001 and 2014. The data of permanent resident population originate from 34 cities and the Statistical Bulletin on National Economic and Social Development published in 2001 and 2013. The travel time, which is calculated based on train schedules, originate from the Train Schedules in April 2000 and May 2013. Taking the year of 2000 as the base period, both the annual GDP and RGDP are adjusted by the GDP indicators. The statistical characteristics of variables are shown in Table 1. 
Table 1. Variable definitions and smmary statistics.

\begin{tabular}{|c|c|c|c|c|c|}
\hline Variable & Definition & Year & Observations & Mean & SD \\
\hline \multirow[b]{2}{*}{$R G D P$} & \multirow[b]{2}{*}{ Per capital GDP (Yuan) } & 2000 & 34 & 16104.62 & 8907.92 \\
\hline & & 2013 & 34 & 64614.51 & 29586.4 \\
\hline \multirow{2}{*}{ HJPOP } & \multirow{2}{*}{$\begin{array}{l}\text { Year-end total population } \\
(10,000 \text { persons })\end{array}$} & 2000 & 34 & 636.0815 & 525.102 \\
\hline & & 2013 & 34 & 746.9382 & 557.532 \\
\hline \multirow{2}{*}{ CZPOP } & \multirow{2}{*}{$\begin{array}{l}\text { Resident population } \\
(10,000 \text { persons })\end{array}$} & 2000 & 34 & 716.1327 & 499.025 \\
\hline & & 2013 & 34 & 904.0729 & 601.450 \\
\hline \multirow{2}{*}{$B T$} & \multirow[b]{2}{*}{-} & 2000 & 34 & 32.69207 & 13.8460 \\
\hline & & 2013 & 34 & 404.0803 & 206.757 \\
\hline \multirow{2}{*}{ capital } & \multirow{2}{*}{$\begin{array}{l}\text { The ratio of total fixed assets } \\
\text { investment to GDP (\%) }\end{array}$} & 2000 & 34 & 29.01622 & 11.5080 \\
\hline & & 2013 & 34 & 70.80556 & 25.4970 \\
\hline \multirow[t]{2}{*}{ labor } & \multirow{2}{*}{$\begin{array}{l}\text { The ratio of the number of } \\
\text { employment to the total population } \\
\text { at the end of the year }(\%)\end{array}$} & 2000 & 34 & 22.41057 & 15.9159 \\
\hline & & 2013 & 34 & 30.18132 & 23.9617 \\
\hline \multirow{2}{*}{$e d u$} & \multirow{2}{*}{$\begin{array}{l}\text { The ratio of the sum of science and } \\
\text { technology expenditure and } \\
\text { educational expenditure to the } \\
\text { local public expenditure (\%) }\end{array}$} & 2000 & 34 & 12.16245 & 4.79237 \\
\hline & & 2013 & 34 & 19.23094 & 3.04394 \\
\hline \multirow{2}{*}{ infras } & \multirow{2}{*}{ Road area per capita $\left(\mathrm{m}^{2}\right)$} & 2000 & 34 & 5.888235 & 2.65636 \\
\hline & & 2013 & 34 & 14.48676 & 5.91455 \\
\hline \multirow[t]{2}{*}{ trans } & $\begin{array}{l}\text { The freight capacity of highways, } \\
\text { waterways, airways and }\end{array}$ & 2000 & 34 & 12716.09 & 10126.8 \\
\hline & ordinary railways $(10,000 \mathrm{t})$ & 2013 & 34 & 32087.97 & 22424.8 \\
\hline \multirow{2}{*}{ industry } & \multirow{2}{*}{$\begin{array}{l}\text { The ratio of second industrial } \\
\text { value to GDP (\%) }\end{array}$} & 2000 & 34 & 45.74412 & 5.42560 \\
\hline & & 2013 & 34 & 45.49529 & 7.68960 \\
\hline ur & $\begin{array}{l}\text { The ratio of non agricultural } \\
\text { population to the total population } \\
\text { at the end of the year }(\%)\end{array}$ & 2000 & 34 & 0.4693425 & 0.155322 \\
\hline region & $\begin{array}{l}\text { Dummy Variable: } 1=\text { located in } \\
\text { the eastern and central regions, } \\
0=\text { located in the western regions }\end{array}$ & - & 34 & 0.5588235 & 0.503995 \\
\hline
\end{tabular}

\section{Analysis of Empirical Results}

\subsection{Impact on RGDP}

\subsubsection{Analysis of Full Sample Regression Results}

Equations (1)-(7) in Table 2 regress all city samples selected in this paper. No control variable is added to Equation (1), and the BT coefficient is negative, but not significant. Other control variables are gradually added to Equations (2)-(7), and the BT coefficient is negative and stable. Besides, the coefficient of other control variables is also significant and the sign is stable, showing that the high-speed railway has not only failed to promote economic growth, but has exerted a negative impact. 
Table 2. Full sample regression results for per capita GDP.

\begin{tabular}{|c|c|c|c|c|c|c|c|}
\hline \multicolumn{8}{|c|}{ Explained variable: $R G D P$} \\
\hline & (1) & (2) & (3) & (4) & (5) & (6) & (7) \\
\hline \multirow[t]{2}{*}{$B T$} & -0.072 & $-0.202^{\star}$ & $-0.223^{\star *}$ & $-0.231^{\star *}$ & $-0.283^{* * *}$ & $-0.279^{* * *}$ & $-0.286^{* * *}$ \\
\hline & $(0.109)$ & $(0.112)$ & $(0.101)$ & $(0.095)$ & $(0.099)$ & $(0.092)$ & $(0.093)$ \\
\hline \multirow[t]{2}{*}{ capital } & & $0.147^{* * *}$ & $0.133^{* * *}$ & $0.103^{* *}$ & $0.154^{* * *}$ & $0.112^{\star * *}$ & $0.126^{* * *}$ \\
\hline & & $(0.049)$ & $(0.043)$ & $(0.042)$ & $(0.046)$ & $(0.040)$ & $(0.045)$ \\
\hline \multirow[t]{2}{*}{ labor } & & $0.141^{*}$ & $0.200^{* *}$ & $0.198^{* * *}$ & $0.223^{* * *}$ & $0.221^{\star * *}$ & $0.219^{* * *}$ \\
\hline & & $(0.078)$ & $(0.076)$ & $(0.071)$ & $(0.074)$ & $(0.068)$ & $(0.069)$ \\
\hline \multirow[t]{2}{*}{$e d u$} & & & $-0.283^{* *}$ & $-0.251^{\star \star}$ & $-0.349^{* * *}$ & $-0.312^{\star * *}$ & $-0.314^{* * *}$ \\
\hline & & & $(0.109)$ & $(0.102)$ & $(0.107)$ & $(0.101)$ & $(0.102)$ \\
\hline \multirow[t]{2}{*}{ infras } & & & & $0.176^{\star *}$ & & $0.162^{\star *}$ & $0.161^{\star *}$ \\
\hline & & & & $(0.077)$ & & $(0.073)$ & $(0.074)$ \\
\hline \multirow[t]{2}{*}{ trans } & & & & & $0.082^{* *}$ & $0.072^{\star *}$ & $0.075^{* *}$ \\
\hline & & & & & $(0.037)$ & $(0.034)$ & $(0.035)$ \\
\hline \multirow[t]{2}{*}{ industry } & & & & & -0.122 & & -0.116 \\
\hline & & & & & $(0.178)$ & & $(0.166)$ \\
\hline \multirow[t]{2}{*}{ Constant } & $1.601^{* * *}$ & $1.745^{\star * *}$ & $1.949^{* * *}$ & $1.820^{\star * *}$ & $2.015^{* * *}$ & $1.888^{* * *}$ & $1.891^{* * *}$ \\
\hline & $(0.269)$ & $(0.267)$ & $(0.255)$ & $(0.245)$ & $(0.244)$ & $(0.233)$ & $(0.235)$ \\
\hline Observations & 34 & 34 & 33 & 33 & 33 & 33 & 33 \\
\hline R-squared & 0.013 & 0.328 & 0.423 & 0.516 & 0.517 & 0.586 & 0.594 \\
\hline
\end{tabular}

Notes: (1) The number of parentheses is standard deviation; (2) ${ }^{* *}$ Significant at the $1 \%$ level, ${ }^{*}$ Significant at the $5 \%$ level, ${ }^{*}$ Significant at $10 \%$ level.

According to the theoretical speculation that the development of high-speed railways can promote economic growth, the BT effect should be positive. While based on the regression Equations (1)-(7), BT coefficients are all negative, thus violating our expectations. The negative BT effect may be caused by the following reasons: 1) High-speed railways only focus on passenger transport, thus ignoring the freight, which is more important than the passenger transport in the economic development. As a result, the impact of high speed railways on economic growth is not as good as that of ordinary railways. What's more, in terms of the impact on RGDP, the effect brought by high-speed railways is negative when compared with the capital, labor, infrastructure and other transportation. 2) The two periods selected in this paper are 2000 and 2013. During the 14 years, Chinese railways have experienced four major speed increases, respectively in 2000, 2001, 2004 and 2007, while the development of high-speed railways in China is temporarily stalled after Qin-Chen interurban railway. That is to say, there is no new development for a long time until 2008-Beijing-Tianjin interurban railway. It has six years' interval between 2008 and 2013, while such interval is shorter than 14 years. As a result, the impact of high-speed railways is inferior to that of speed increases. 3) The impact of a single high-speed railway 
line is minimal on the social economy. So, it is necessary to establish a balanced high-speed railway network to extend in all directions. The development of high-speed railways in China is unbalanced. By 2013, the urban agglomerations with high-speed railways contain Beijing-Tianjin-Hebei Region, the Yangtze River Delta, the Pearl River Delta and the middle reaches of Yangtze River. However, the cities selected are distributed evenly across the country, the high-speed railway effect is not accurate enough.

The impact of other control variables on urban per capita GDP is basically in line with expectations. The input of capital and labor force has a positive influence on regional economic growth. The increase in per capita road area also contributes to economic growth; The development of other modes of transport, such as expressways and aviation, which are manifested by the increase in freight volume, is conducive to reducing obstacles and promoting the effective flow of resources, thus to promote the economic growth. The industrial structure variable uses the proportion of the secondary industry. Due to the high energy consumption and high emission of the secondary industry, the optimization of the industrial structure gradually reduces the proportion of the secondary industry. Therefore, the effect of the industrial structure is negative in line with the law of economic development. The coefficient of science and education is negative, which is not in line with expectations, but one explanation for it is that the investment of science and education represents government expenditure, and the increase of government expenditure or excessive intervention in the market will lead to the "Crowding out effect".

\subsubsection{Analysis of Grouping Regression Results}

The BT effect of the whole sample regression was significantly negative, which was inconsistent with the expectation. So is there a difference in HSR due to different levels of HSR development? Or does high-speed rail have a different effect on cities with different levels of economic development? The following 34 cities are divided into two groups for an in-depth study.

According to the value of $\Delta 2000-2013 \ln$ (BTi), 34 cities are sorted from small to large, as shown in Table 3. Divide it into two groups from the middle, the first 17 cities for one, and the next 17 cities for the other. $\Delta 2000-2013 \ln (\mathrm{BTi})$ represents the urban market potential improvement, according to the construction of China's high-speed rail project in recent years, it can be judged that between 2000 and 2013, the development or accessibility of high-speed rail in the first group of cities increased slowly compared with the latter one. From the perspective of urban economic strength, the former group of cities is mostly located in the western region, and the economic development is relatively backward, on the contrary, the latter group is stronger. The first group is called the backward group, and the latter group is called the developed group.

Regression estimates were performed in both groups and the results were in Table 4. The Equation (1) only has BT variables, and the system (2)-(4) gradually add other control variables. Although some BT coefficients are significant 
Table 3. The value of $\Delta 2000-2013 \ln (\mathrm{BTi})$.

\begin{tabular}{cccccc}
\hline Ranking & City & $\Delta 2000-2013 \ln (\mathrm{BTi})$ & Ranking & City & $\Delta 2000-2013 \ln (\mathrm{BTi})$ \\
\hline 1 & Hohhot & 1.8862 & 18 & Zhengzhou & 2.4601 \\
2 & Kunming & 1.9803 & 19 & Hangzhou & 2.4778 \\
3 & Urumqi & 2.0354 & 20 & Changsha & 2.5157 \\
4 & Yinchuan & 2.0494 & 21 & Nanjing & 2.5272 \\
5 & Lanzhou & 2.0660 & 22 & Jinan & 2.5516 \\
6 & Xining & 2.1111 & 23 & Ningbo & 2.5568 \\
7 & Guiyang & 2.1185 & 24 & Shanghai & 2.6036 \\
8 & Dalian & 2.1206 & 25 & Chengdu & 2.6120 \\
9 & Changchun & 2.1252 & 26 & Beijing & 2.6125 \\
10 & Harbin & 2.1722 & 27 & Hefei & 2.6183 \\
11 & Shijiazhuang & 2.1798 & 28 & Shenzhen & 2.7254 \\
12 & Nanning & 2.2059 & 29 & Guangzhou & 2.8078 \\
13 & Shenyang & 2.2166 & 30 & Chongqing & 2.8257 \\
14 & Taiyuan & 2.3156 & 31 & Nanchang & 3.0196 \\
15 & Tianjin & 2.3790 & 32 & Xiamen & 3.0343 \\
16 & Qingdao & Xi'an & 2.3932 & 34 & Wuhan \\
17 & 2.3961 & Fuzhou & 3.0584 \\
\hline
\end{tabular}

Notes: Because of Tianjin, Shijiazhuang etc. cites had become national transportation hubs in the base period of 2000, the improvement of these cities' accessibility in 2000-2013 was not as high as that of some cities which had been lagging behind, so they were divided into backward groups.

Table 4. Grouping regression results for per capita GDP.

\begin{tabular}{|c|c|c|c|c|c|c|c|c|}
\hline \multicolumn{9}{|c|}{ Explained variable: $R G D P$} \\
\hline & \multicolumn{2}{|c|}{ (1) } & \multicolumn{2}{|c|}{ (2) } & \multicolumn{2}{|c|}{ (3) } & \multicolumn{2}{|c|}{$(4)$} \\
\hline & $\begin{array}{c}\text { Backward } \\
\text { group }\end{array}$ & $\begin{array}{l}\text { Developed } \\
\text { group }\end{array}$ & $\begin{array}{l}\text { Backward } \\
\text { group }\end{array}$ & $\begin{array}{l}\text { Developed } \\
\text { group }\end{array}$ & $\begin{array}{c}\text { Backward } \\
\text { group }\end{array}$ & $\begin{array}{l}\text { Developed } \\
\text { group }\end{array}$ & $\begin{array}{c}\text { Backward } \\
\text { group }\end{array}$ & $\begin{array}{c}\text { Developed } \\
\text { group }\end{array}$ \\
\hline \multirow[t]{2}{*}{$B T$} & -0.147 & 0.163 & -0.383 & 0.039 & $-0.736^{* * *}$ & -0.080 & $-0.672^{* *}$ & -0.205 \\
\hline & $(0.337)$ & $(0.238)$ & $(0.316)$ & $(0.223)$ & $(0.228)$ & $(0.173)$ & $(0.259)$ & $(0.164)$ \\
\hline \multirow[t]{2}{*}{ capital } & & & & & $0.327^{\star * *}$ & $0.149^{* *}$ & $0.288^{* *}$ & $0.151^{* * *}$ \\
\hline & & & & & $(0.084)$ & $(0.049)$ & $(0.109)$ & $(0.043)$ \\
\hline \multirow[t]{2}{*}{ labor } & & & $0.396^{\star *}$ & 0.130 & $0.356^{\star \star \star}$ & 0.020 & $0.360^{\star * \star}$ & -0.039 \\
\hline & & & $(0.155)$ & $(0.117)$ & $(0.103)$ & $(0.095)$ & $(0.107)$ & $(0.089)$ \\
\hline \multirow[t]{2}{*}{$e d u$} & & & $-0.312^{*}$ & 0.004 & $-0.566^{* * *}$ & 0.073 & $-0.563^{* * *}$ & 0.130 \\
\hline & & & $(0.172)$ & $(0.164)$ & $(0.131)$ & $(0.126)$ & $(0.136)$ & $(0.114)$ \\
\hline \multirow[t]{2}{*}{ infras } & & & & & & & 0.104 & $0.173^{*}$ \\
\hline & & & & & & & $(0.177)$ & $(0.087)$ \\
\hline \multirow[t]{2}{*}{ trans } & & & 0.068 & 0.077 & $0.082^{*}$ & 0.072 & 0.076 & 0.077 \\
\hline & & & $(0.062)$ & $(0.071)$ & $(0.041)$ & $(0.054)$ & $(0.044)$ & $(0.047)$ \\
\hline \multirow[t]{2}{*}{ industry } & & & 0.350 & $-0.636^{*}$ & $0.565^{\star *}$ & -0.433 & 0.441 & -0.257 \\
\hline & & & $(0.327)$ & $(0.338)$ & $(0.223)$ & $(0.263)$ & $(0.313)$ & $(0.248)$ \\
\hline \multirow[t]{2}{*}{ Constant } & $1.780^{* *}$ & 0.948 & $2.350^{\star * *}$ & $1.195^{\star}$ & $2.889^{\star * \star}$ & $1.412^{\star *}$ & $2.700^{\star * \star}$ & $1.572^{\star * *}$ \\
\hline & $(0.738)$ & $(0.648)$ & $(0.704)$ & $(0.636)$ & $(0.486)$ & $(0.485)$ & $(0.597)$ & $(0.434)$ \\
\hline Observations & 17 & 17 & 17 & 17 & 17 & 17 & 17 & 17 \\
\hline R-squared & 0.013 & 0.030 & -0.383 & 0.040 & 0.800 & 0.759 & 0.808 & 0.832 \\
\hline
\end{tabular}

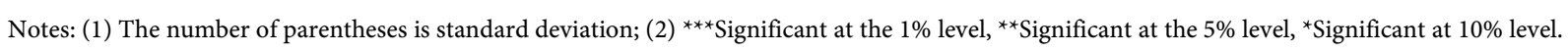


and some are not, the symbols are noteworthy: the BT coefficients of the backward group are negative and of the developed group are positive, indicating that the nationwide advance of the HSR has a positive effect on the economically developed cities, while economically underdeveloped cities have a negative effect. The construction of high-speed railway began in the eastern and central economic cities and has formed a high-speed railway network. Cities with relatively backward economy in the west have not yet got through the high-speed railways or have experienced high-speed rail lines with few trips, low stop frequencies. The unbalanced development of high-speed rail has resulted in different positive and negative effects. This proves the previous speculation that the high-speed rail is different due to the different development levels of high-speed rail. The development of high-speed rail is conducive to the further rise of big cities, but not to the development of small and medium-sized cities.

In (3) and (4), the coefficient of BT variable in backward group is significantly negative while the coefficient of BT variable in developed group is positive but not obvious, which indicates that the construction of high-speed railway in China has a significant negative effect on the relatively backward cities in the remote economy. The high-speed railway has a growth effect on the developed regions, but it is not significant, further confirmed that China's high-speed rail development has brought economic growth to the eastern and central cities without benefiting the remote and backward areas.

In terms of controlling variables, capital and labor as well as the whole sample regression results are the same as positive effects, and the backward groups are more prominent, which means that capital and labor are more important to the backward region, and the marginal output of the production factors is greater. The coefficients of the two groups of urban science and education levels are converse, the backward group is negative while the developed one is positive for that the backward region is an extensive economy which is driven by capital and labor and it has a low level of investment in science and education, consequently lead to low economic growth; The developed areas are intensive economies with a high level of investment in science and education, besides, the use of knowledge and technological also help to achieve economic growth. The infrastructure effects of the two groups are positive and the developed groups are significant, which reflects that the infrastructure of developed cities is better than the backward cities and it has a greater effect on economic growth. The coefficient of industrial structure variables in the two groups of cities is opponent. The economic growth engine of the backward cities is still the secondary industry, so it is the positive effect, while the developed cities start to turn to the tertiary industry, so it is negative.

\subsection{The Impact on Population}

\subsubsection{Analysis of Full Sample Regression Results}

In this paper, the population of the city at the end of the year was selected as the population quantity, and the regression results showed that the coefficients of 
$\mathrm{BT}$ variables were positive, but not significant ${ }^{2}$. The reason lies in the limitation of the household registration system in China, especially big cities like Beijing, Shanghai and Guangzhou need to meet with requirements and limit settle indicators. The natural growth of the population is also controlled by China Family Planning. The population of the household registration is affected by the system and the changes in the development of HSR are not very strong. Although the development of high-speed rail has no significant impact on the household registration population, the improvement of accessibility is in favor of population mobility, and the mobility of urban population can be reflected from the resident population. Regressing with the resident population as an explanatory variable, Table 5 is the estimation result. The effect of $\mathrm{BT}$ variable is positive, which confirms that the development of high-speed rail has enhanced liquidity and brought population growth. The cities chosen by this article are the provincial or sub-provincial cities, which are the center of the region. The employment opportunities are relatively better, and the improvement of transportation is conducive to the expansion of radiation and the inflow of labor from surrounding areas.

Table 5. Full sample regression results for resident population.

\begin{tabular}{|c|c|c|c|c|c|c|c|}
\hline \multicolumn{8}{|c|}{ Explained variable: $C Z P O P$} \\
\hline & (1) & (2) & (3) & (4) & (5) & (6) & (7) \\
\hline \multirow[t]{2}{*}{$B T$} & 0.101 & $0.151^{\star}$ & $0.165^{\star *}$ & $0.163^{\star *}$ & $0.161^{\star}$ & $0.168^{* *}$ & 0.133 \\
\hline & $(0.088)$ & $(0.089)$ & $(0.080)$ & $(0.078)$ & $(0.081)$ & $(0.073)$ & $(0.079)$ \\
\hline \multirow[t]{2}{*}{ capital } & & & $-0.110^{* * *}$ & $-0.092^{* * *}$ & $-0.104^{\star \star \star}$ & $-0.0902^{\star * *}$ & \\
\hline & & & $(0.023)$ & $(0.024)$ & $(0.028)$ & $(0.028)$ & \\
\hline \multirow[t]{2}{*}{ labor } & & -0.082 & -0.064 & -0.061 & -0.064 & -0.067 & $-0.0811^{\star}$ \\
\hline & & $(0.058)$ & $(0.045)$ & $(0.055)$ & $(0.046)$ & $(0.047)$ & $(0.044)$ \\
\hline \multirow[t]{2}{*}{$e d u$} & & 0.015 & & 0.0006 & & & \\
\hline & & $(0.061)$ & & $(0.0723)$ & & & \\
\hline \multirow[t]{2}{*}{ infras } & & & & $-0.083^{\star}$ & & $-0.085^{\star}$ & $-0.128^{* *}$ \\
\hline & & & & $(0.048)$ & & $(0.046)$ & $(0.055)$ \\
\hline \multirow[t]{2}{*}{ trans } & & & & & & & $0.071^{\star *}$ \\
\hline & & & & & & & $(0.032)$ \\
\hline \multirow[t]{2}{*}{ industry } & & -0.181 & & & -0.041 & -0.038 & $-0.232^{* *}$ \\
\hline & & $(0.115)$ & & & $(0.110)$ & $(0.109)$ & $(0.103)$ \\
\hline \multirow[t]{2}{*}{ Constant } & -0.005 & -0.114 & -0.044 & 0.019 & -0.040 & 0.009 & -0.019 \\
\hline & $(0.212)$ & $(0.203)$ & $(0.187)$ & $(0.196)$ & $(0.187)$ & $(0.175)$ & $(0.200)$ \\
\hline Observations & 34 & 33 & 34 & 33 & 34 & 34 & 34 \\
\hline R-squared & 0.055 & 0.138 & 0.347 & 0.355 & 0.349 & 0.387 & 0.406 \\
\hline
\end{tabular}

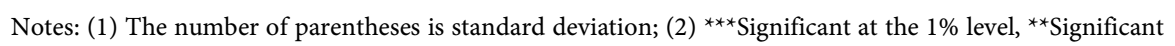
at the $5 \%$ level, ${ }^{\star}$ Significant at $10 \%$ level.

${ }^{2}$ In order to save the length, the regression results are omitted here. 
The effect of capital and infrastructure in control variables is negative. Capital and infrastructure should be positive. Why they are negative? The Solow Growth Model suggests that the increase of population growth will reduce the homeostasis of per capita capital and thus reduce the steady state of production per capita. Under the vigorous development of the big cities in our country, the resident population is over-inflated. The urban permanent population is far beyond the capacity of the city, so the capital and infrastructure have negative effects on the resident population. The coefficients of other traffic variables are clearly positive, which means that the convenience of roads, airlines, and transportation are also conducive to population mobility. The coefficient of industrial structure is significantly negative as the second industry's ability to absorb labor is not as good as the third industry, so the effect on population growth is negative.

\subsubsection{Analysis of Grouping Regression Results}

When studying the impact of high-speed railway on GDP per capita, the HSR effects in the developed and the backward regions are diametrically opposite, if so, will the impact on the population change be different due to the uneven development of the HSR or the regional economic? According to the same way, the city is divided into two groups to return to the population of permanent residents, the results are shown in Table 6.

Table 6. Grouping regression results for resident population.

\begin{tabular}{|c|c|c|c|c|c|c|c|c|}
\hline \multicolumn{9}{|c|}{ Explained variable: $C Z P O P$} \\
\hline & \multicolumn{2}{|c|}{ (1) } & \multicolumn{2}{|c|}{$(2)$} & \multicolumn{2}{|c|}{ (3) } & \multicolumn{2}{|c|}{$(4)$} \\
\hline & $\begin{array}{c}\text { Backward } \\
\text { group }\end{array}$ & $\begin{array}{l}\text { Developed } \\
\text { group }\end{array}$ & $\begin{array}{l}\text { Backward } \\
\text { group }\end{array}$ & $\begin{array}{l}\text { Developed } \\
\text { group }\end{array}$ & $\begin{array}{l}\text { Backward } \\
\text { group }\end{array}$ & $\begin{array}{l}\text { Developed } \\
\text { group }\end{array}$ & $\begin{array}{l}\text { Backward } \\
\text { group }\end{array}$ & $\begin{array}{l}\text { Developed } \\
\text { group }\end{array}$ \\
\hline \multirow[t]{2}{*}{$B T$} & 0.044 & -0.023 & $0.373^{*}$ & 0.046 & $0.368^{*}$ & -0.111 & 0.315 & -0.035 \\
\hline & $(0.202)$ & $(0.184)$ & $(0.214)$ & $(0.192)$ & $(0.219)$ & $(0.141)$ & $(0.253)$ & $(0.158)$ \\
\hline \multirow[t]{2}{*}{ capital } & & & $-0.184^{\star * \star}$ & $-0.089^{*}$ & $-0.179^{* * *}$ & $-0.100^{* * *}$ & -0.180 & $-0.089^{* *}$ \\
\hline & & & $(0.076)$ & $(0.056)$ & $(0.079)$ & $(0.039)$ & $(0.106)$ & $(0.041)$ \\
\hline \multirow[t]{2}{*}{ labor } & & & -0.091 & -0.053 & -0.070 & -0.028 & -0.051 & -0.011 \\
\hline & & & $(0.090)$ & $(0.114)$ & $(0.098)$ & $(0.080)$ & $(0.105)$ & $(0.086)$ \\
\hline \multirow[t]{2}{*}{$e d u$} & & & 0.087 & -0.056 & 0.0701 & $-0.271^{\star * *}$ & 0.069 & $-0.273^{* * *}$ \\
\hline & & & $(0.121)$ & $(0.124)$ & $(0.127)$ & $(0.104)$ & $(0.133)$ & $(0.110)$ \\
\hline \multirow[t]{2}{*}{ infras } & & & & & & & -0.053 & -0.055 \\
\hline & & & & & & & $(0.173)$ & $(0.084)$ \\
\hline \multirow[t]{2}{*}{ trans } & & & & & 0.025 & $0.163^{* * *}$ & 0.029 & $0.171^{* * *}$ \\
\hline & & & & & $(0.040)$ & $(0.044)$ & $(0.043)$ & $(0.046)$ \\
\hline \multirow[t]{2}{*}{ industry } & & & & & & & -0.157 & 0.203 \\
\hline & & & & & & & $(0.306)$ & $(0.238)$ \\
\hline \multirow[t]{2}{*}{ Constant } & 0.108 & 0.343 & -0.463 & 0.289 & -0.474 & 0.625 & -0.303 & 0.416 \\
\hline & $(0.443)$ & $(0.503)$ & $(0.452)$ & $(0.531)$ & $(0.464)$ & $(0.383)$ & $(0.582)$ & $(0.417)$ \\
\hline Observations & 17 & 17 & 17 & 17 & 17 & 17 & 17 & 17 \\
\hline R-squared & 0.003 & 0.001 & 0.405 & 0.292 & 0.426 & 0.682 & 0.486 & 0.735 \\
\hline
\end{tabular}

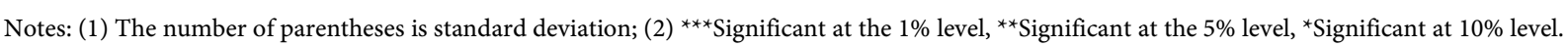


The symbolic stability of the backward coefficient BT coefficients is positive, satisfying the $15 \%$ of significance level. The laggard cities are still in the center of their own province, and the development of high-speed rail will help improve accessibility. Expanding its radiation range can bring in population inflows. The symbols of the BT coefficient in developed groups are unstable. They are positive before joining trans variables and negative after joining trans variables but unclear, indicating that the real cause of population growth in developed regions is the increase in demand for labor and the convenience of other transportation development of non-high-speed railway. The different effects of HSR development on backward groups and developed groups show that transportation plays different roles in different stages of economic development. In the early stages of economic development, transport development has obviously promoted economic growth. When the economy reaches a certain level, however, due to diminishing marginal utility, the effect on economic growth gradually became insignificant.

\section{Sample Selection and Endogenous Problems}

Of the 34 cities we selected, there were 7 cities with no high-speed trains in the end of $2013^{3}$. Considering whether it will change by excluding these seven cities to re-estimate the high iron effect and comparing with the regression results of the whole sample. To further test the robustness of the previous empirical results, the following is the data after the deletion of seven cities and a return to the GDP per capita and the population of the population, and it turns out to be in Table 7. It can be seen that the variable BT is significantly negative for GDP per capita and for the resident population is positive on the other hand, which is basically the same as that of the whole sample regression. The symbol of control variables is also consistent, which verifies the negative effect of high-speed rail on overall economic growth, but directly promotes the growth of urban permanent population.

As the planning of high-speed rail lines and the setting of high-speed rail stations are affected by the actual situation in the region and the direction of government policies, the BT variables may be endogenous. This article considers the possible use of instrumental variables to reduce endogeneity errors or inconsistencies. The selection of tool variables has two criteria: one is that the variable has to do with an internal explanation; the second is that the variable is not related to the random error term. So two instrumental variables are selected, and one tool variable is the urbanization level of the city in 2000 , which is measured by the proportion of the non-agricultural population in the total population, and the other tool variable is the region belonging to the city, which belongs to the middle eastern region and the value is 1 , and the western region is 0 . The estimated results are as in Table 8.

${ }^{3}$ The seven cities are: Urumqi, Xining, Yinchuan, Lanzhou, Guiyang, Kunming, Huhhot. 
Table 7. Regression results after deleting part of the sample.

\begin{tabular}{|c|c|c|c|c|c|c|}
\hline \multirow{2}{*}{ Explained variable } & \multicolumn{3}{|c|}{$R G D P$} & \multicolumn{3}{|c|}{ CZPOP } \\
\hline & (1) & (2) & (3) & (4) & (5) & (6) \\
\hline \multirow[t]{2}{*}{$B T$} & $-0.306^{\star *}$ & $-0.331^{* * *}$ & $-0.318^{* * *}$ & $0.160^{*}$ & $0.143^{*}$ & 0.093 \\
\hline & $(0.116)$ & $(0.010)$ & $(0.091)$ & $(0.087)$ & $(0.079)$ & $(0.081)$ \\
\hline \multirow[t]{2}{*}{ capital } & & $0.110^{\star *}$ & 0.076 & & & -0.061 \\
\hline & & $(0.039)$ & $(0.045)$ & & & $(0.040)$ \\
\hline \multirow[t]{2}{*}{ labor } & $0.164^{*}$ & $0.150^{*}$ & $0.120^{*}$ & -0.008 & -0.0327 & 0.017 \\
\hline & $(0.092)$ & $(0.078)$ & $(0.072)$ & $(0.063)$ & $(0.058)$ & $(0.064)$ \\
\hline \multirow[t]{2}{*}{$e d u$} & $-0.334^{* *}$ & $-0.376^{\star * *}$ & $-0.273^{\star *}$ & & & -0.107 \\
\hline & $(0.141)$ & $(0.124)$ & $(0.124)$ & & & $(0.065)$ \\
\hline \multirow[t]{2}{*}{ infras } & & & $0.181^{\star *}$ & -0.098 & -0.091 & -0.157 \\
\hline & & & $(0.073)$ & $(0.067)$ & $(0.061)$ & $(0.110)$ \\
\hline \multirow[t]{2}{*}{ trans } & & $0.098^{* *}$ & $0.089^{\star *}$ & & $0.068^{\star *}$ & $0.080^{\star *}$ \\
\hline & & $(0.036)$ & $(0.033)$ & & $(0.028)$ & $(0.030)$ \\
\hline \multirow[t]{2}{*}{ industry } & $0.333^{\star}$ & & 0.052 & $-0.283^{\star *}$ & $-0.335^{\star * *}$ & -0.114 \\
\hline & $(0.187)$ & & $(0.180)$ & $(0.128)$ & $(0.118)$ & $(0.160)$ \\
\hline \multirow[t]{2}{*}{ Constant } & $2.341^{\star * *}$ & $2.219^{\star * *}$ & $2.107^{\star * *}$ & -0.074 & -0.100 & 0.151 \\
\hline & $(0.298)$ & $(0.262)$ & $(0.259)$ & $(0.215)$ & $(0.196)$ & $(0.230)$ \\
\hline Observations & 27 & 26 & 26 & 27 & 27 & 26 \\
\hline R-squared & 0.369 & 0.568 & 0.677 & 0.375 & 0.505 & 0.571 \\
\hline
\end{tabular}

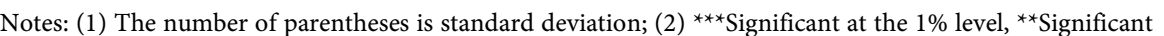
at the $5 \%$ level, ${ }^{*}$ Significant at $10 \%$ level.

Table 8. IV estimation results.

\begin{tabular}{|c|c|c|c|c|c|c|}
\hline \multirow{2}{*}{ Explained variable } & \multicolumn{3}{|c|}{$C Z P O P$} & \multicolumn{3}{|c|}{$R G D P$} \\
\hline & (1) & (2) & (3) & (4) & (5) & (6) \\
\hline \multirow[t]{2}{*}{$B T$} & $0.324^{* * *}$ & $0.313^{* * *}$ & $0.317^{* * *}$ & $-0.312^{\star *}$ & $-0.263^{\star *}$ & $-0.281^{\star *}$ \\
\hline & $(0.104)$ & $(0.107)$ & $(0.110)$ & $(0.129)$ & $(0.116)$ & $(0.116)$ \\
\hline \multirow[t]{2}{*}{ capital } & $-0.090^{\star * *}$ & $-0.082^{\star *}$ & $-0.084^{\star *}$ & $0.140^{* * *}$ & $0.112^{* * *}$ & $0.126^{* * *}$ \\
\hline & $(0.033)$ & $(0.037)$ & $(0.037)$ & $(0.037)$ & $(0.036)$ & $(0.039)$ \\
\hline \multirow[t]{2}{*}{ labor } & $-0.134^{* *}$ & $-0.132^{* *}$ & $-0.129^{*}$ & $0.242^{* * *}$ & $0.214^{* * *}$ & $0.217^{* * *}$ \\
\hline & $(0.058)$ & $(0.057)$ & $(0.066)$ & $(0.078)$ & $(0.071)$ & $(0.070)$ \\
\hline \multirow[t]{2}{*}{$e d u$} & & & -0.0013 & $-0.358^{\star * *}$ & $-0.307^{\star * *}$ & $-0.312^{* * *}$ \\
\hline & & & $(0.087)$ & $(0.101)$ & $(0.093)$ & $(0.092)$ \\
\hline \multirow[t]{2}{*}{ infras } & $-0.101^{*}$ & $-0.101^{\star}$ & $-0.100^{\star}$ & & $0.162^{* *}$ & $0.161^{\star *}$ \\
\hline & $(0.060)$ & $(0.059)$ & $(0.061)$ & & $(0.065)$ & $(0.064)$ \\
\hline \multirow[t]{2}{*}{ trans } & $0.0487^{\star}$ & $0.052^{*}$ & $0.056^{*}$ & $0.082^{* *}$ & $0.070^{* *}$ & $0.074^{\star *}$ \\
\hline & $(0.026)$ & $(0.027)$ & $(0.030)$ & $(0.034)$ & $(0.0312)$ & $(0.031)$ \\
\hline
\end{tabular}




\section{Continued}

\begin{tabular}{|c|c|c|c|c|c|c|}
\hline \multirow[t]{2}{*}{ industry } & & -0.057 & -0.0087 & & & -0.115 \\
\hline & & $(0.125)$ & $(0.138)$ & & & $(0.146)$ \\
\hline \multirow[t]{2}{*}{ Constant } & -0.389 & -0.374 & -0.390 & $2.098^{\star * *}$ & $1.851^{\star * *}$ & $1.881^{\star * *}$ \\
\hline & $(0.244)$ & $(0.244)$ & $(0.266)$ & $(0.311)$ & $(0.283)$ & $(0.281)$ \\
\hline Observations & 34 & 34 & 33 & 33 & 33 & 33 \\
\hline R-squared & 0.366 & 0.384 & 0.350 & 0.505 & 0.586 & 0.594 \\
\hline Huasman test & 0.013 & 0.016 & 0.003 & 0.698 & 0.847 & 0.957 \\
\hline D-W-Htest & 0.023 & 0.030 & 0.006 & 0.732 & 0.868 & 0.964 \\
\hline $\begin{array}{l}\text { Kleibergen-Paap } \\
\text { rk LM test }\end{array}$ & 0.003 & 0.012 & 0.009 & 0.003 & 0.004 & 0.009 \\
\hline \multirow{2}{*}{$\begin{array}{l}\text { Kleibergen-Paap } \\
\text { rk Wald F value }\end{array}$} & 10.718 & 8.883 & 9.540 & 10.184 & 10.820 & 9.540 \\
\hline & 8.75 & 8.75 & 8.75 & 8.75 & 8.75 & 8.75 \\
\hline Cragg-Donald & 12.081 & 9.992 & 11.528 & 11.829 & 12.196 & 11.528 \\
\hline Wald F value & 11.59 & 8.75 & 11.59 & 11.59 & 11.59 & 11.59 \\
\hline Hansen J test & 0.229 & 0.209 & 0.187 & 0.902 & 0.966 & 0.968 \\
\hline Sargan test & 0.181 & 0.180 & 0.140 & 0.876 & 0.956 & 0.958 \\
\hline
\end{tabular}

Notes: (1) Hausman test, D-W-H test, Kleibergen-Paap rk LM test, Hansen J test and Sargan test all report $P$ value; (2) Kleibergen-Paap rk Wald F test and Cragg-Donald Wald F test report F value shown at the top raw and the critical values of the two tests modified by Stock and Yogo (2002) shown at the bottom raw. $15 \%$ level is 11.59 , at $20 \%$ level is 8.75 .

For the regression of urban permanent population, Huasman test and DWH test reject the original hypothesis at 5\% significance level, indicating endogeneity. For the regression of GDP per capita in the region, Huasman test or DWH inspection cannot reject the original hypothesis, indicating that there are no endogenous explanatory variables. The Kleibergen-Pak rk LM test, the Kleibergen-Pak rk Wald F test and the Cragg-Donald Wald F test were all used to test for the presence of weak instrumental variables, both for the resident population and the regional GDP per capita. The test results showed that the instrumental variables are not a weak instrumental variable but were considered to be strongly correlated.

The regression results show that the coefficients of the key variables BT and the control variables are significant, and the symbols are consistent with the OLS estimates, which further shows that the HSR effect is significantly negative for the overall economic growth, for the growth of urban permanent population, the HSR effect is significantly positive.

\section{Conclusions}

By using the empirical method, this paper calculated the market potential improvement of the railway travel time in 2000-2013, and added other control variables in the model to analyze the influence of high-speed railway on regional economic growth. 
The construction of high-speed railways in our country started in areas with a high level of economic development. At present, the development of high-speed railways in the eastern, central and western regions is not balanced. The development of high-speed rail in the major cities in the central and eastern parts of China is relatively well developed. The high-speed rail links into a network within the urban agglomerations and between different urban agglomerations. Nevertheless, the construction of the western region is relatively late and the high-speed rail line is single. The results show that high-speed rail has different effects on economic growth in different regions and changes with the development of high-speed rail in the region. For areas that have formed high-speed rail networks, high-speed rail has compressed the space-time distance and promoted exchanges and cooperation among cities, which has had a positive effect. For areas with a relatively backward development of high-speed railways, high-speed rail has exacerbated its marginalization and has had a negative impact. On the whole, high-speed rail has a negative effect on the overall economic growth.

The essence of our population flows is the flow of labor, from the countryside to the city, from the backward regions to the developed regions. The cross-section of the population relies on rail transport, and the transport capacity of the general railway has been unable to satisfy the strong flow of demand, and the importance of high-speed railway specialized in transporting pedestrian flow is growing. The convenience brought by high-speed rail has led more people to migrate from rural areas to urban areas, and the urban permanent population has been on the rise. The growth of the permanent population indirectly reflects that high-speed rail has brought about an increase in urban economic development. The high-speed rail has a negative effect on per capita GDP and positive effect on population. The reason may be that the convenient traffic brought by high-speed rail has a more direct and obvious effect on population concentration, and the motivation for GDP growth is more diverse.

The construction of transportation infrastructure is essentially the construction of large domestic market, which is the platform for the establishment of specialized labor division and mass production and circulation [24]. The role of high-speed rail to regional economic development is not immediately obvious and has long-term effects. The development of high-speed rail has to take a long time to make a final judgment. However, the short-term impact is indicative and alarming, which will provide direction for the future development planning of HSR.

As a developing country, HSR's function to China's economic growth needs the synergistic effects of institutional environment, human capital improvement and technical level of science and education. On the other hand, the space spillover effects of high-speed railway on economic growth should also be taken into consideration. The development of China's high-speed railway should focus on rational distribution especially the backward areas, making it an engine on backward economic development to coordinate and improve the regional eco- 
nomic development pattern of our country rather than cause widen gap between the east and the west.

\section{References}

[1] Wang, J.J., Xu, J. and He, J. (2013) Spatial Impacts of High-Speed Railways in China: A Total-Travel-Time Approach. Environment \& Planning A, 45, 2261-2280. http://hdl.handle.net/10722/203566 https://doi.org/10.1068/a45289

[2] Harris, C.D. (1954) The Market as a Factor in the Localization of Industry in the United States. Annals of the Association of American Geographers, 44, 315-348. http://www.jstor.org/stable/2561395

[3] Hanson, G.H. (2005) Market Potential Increasing Returns and Geographic Concentration. Journal of International Economics, 67, 1-24. https://doi.org/10.1016/j.jinteco.2004.09.008

[4] Krugman, P.R. (1992) Geography and Trade. MIT Press, Cambridge. https://ideas.repec.org/b/mtp/titles/0262610868.html

[5] Zheng, S. and Kahn, M.E. (2013) China's Bullet Trains Facilitate Market Integration and Mitigate the Cost of Mega City Growth. Proceedings of the National Academy of Sciences of the United States of America, 110, 1248-1253.

http://www.pnas.org/content/110/14/E1248.short https://doi.org/10.1073/pnas.1209247110

[6] Rostow, W.W. (1990) Theorists of Economic Growth from David Hume to the Present. Oxford University Press, Oxford.

[7] Fogel, R.W. (1965) Railroads and American Economic Growth: Essays in Econometric History. Canadian Journal of Economics \& Political Science, 31, 611-612. http://www.journals.uchicago.edu/doi/abs/10.1086/450147 https://doi.org/10.2307/139851

[8] Donaldson, D. and Hornbeck, R. (2016) Railroads and American Economic Growth: A "Market Access" Approach. Quarterly Journal of Economics, 131, 799858. https://scholar.harvard.edu/hornbeck/node/29492 https://doi.org/10.1093/qje/qjw002

[9] Vickerman, R. (1997) High-Speed Rail in Europe: Experience and Issues for Future Development. Annals of Regional Science, 31, 21-38. https://doi.org/10.1007/s001680050037

[10] Schade, W. (2006) Assessing Economic Impacts of Large-Scale Transport Infrastructure Projects: Case of Lyon-Turin Corridor. Transportation Research Record Journal of the Transportation Research Board, 1960, 142-151. https://doi.org/10.3141/1960-17

[11] Monzón, A., Ortega, E. and López, E. (2013) Efficiency and Spatial Equity Impacts of High-Speed Rail Extensions in Urban Areas. Cities, 30, 18-30. https://doi.org/10.1016/j.cities.2011.11.002

[12] Kim, H. and Sultana, S. (2015) The Impacts of High-Speed Rail Extensions on Accessibility and Spatial Equity Changes in South Korea From 2004 to 2018. Journal of Transport Geography, 45, 48-61. https://doi.org/10.1016/j.jtrangeo.2015.04.007

[13] Chen, C.L. and Hall, P. (2011) The Impacts of High-Speed Trains on British Economic Geography: A Study of the UK's Intercity 125/225 and Its Effects. Journal of Transport Geography, 19, 689-704. https://doi.org/10.1016/j.jtrangeo.2010.08.010

[14] Cho, T., Kato, H. and Wetwitoo, J. (2016) How Much Has High-Speed Rail Contri- 
buted to Economic Productivity in Japan? Transportation Research Board: TRB 95th Annual Meeting Papers, Washington DC, 10-14 January 2016, 15 p. http://amonline.trb.org/

[15] Albalate, D. and Fageda, X. (2016) High Speed Rail and Tourism: Empirical Evidence from Spain. Transportation Research Part A, 85, 174-185. https://doi.org/10.1016/j.tra.2016.01.009

[16] Zhao, Q.G. (2013) An Analysis of the Mechanism to Reduce Regional Gap by High-Speed Railway. Contemporary Finance \& Economics, 4, 106-112.

[17] Qin, C.L. and Chong, Z.H. (2014) The Development of High Speed Railway and the Economic Agglomeration along the Railway. Inquiry into Economic Issues, 5, 163 169.

[18] Wang, J.F. and Li, Z.G. (2014) An Empirical Analysis of the Impact of Shanghai Hangzhou High Speed Rail on Regional Economic Development along the Line. Inquiry into Economic Issues, 9, 74-77.

[19] Song, W.J., Zhu, Q., Zhu, Y.M., Kong, C.C., Shi, Y.J. and Gu, Y. (2015) The Impacts of High Speed Railways for Different Scale Cities. Economic Geography, 35, 57-63.

[20] Wang, Y.F. and Peng, F.N. (2016) Economic Growth Spillover and Spatial Optimization of High-Speed Railway. China Industrial Economics, 2, 21-36.

[21] Dai, G. (2015) The Impact of Policy Networks on the Urbanization around HighSpeed Railway Stations in China: The Case of Wuhan. Environment and Planning C: Government and Policy, 33, 533-551. https://doi.org/10.1177/0263774X15594016

[22] Chen, X. (2015) A Sustainability Analysis on the Wuhan-Guangzhou High-Speed Railway in China. International Journal of Sustainable Transportation, 9, 348-363. https://doi.org/10.1080/15568318.2013.797526

[23] Yao, W. and Meng, N. (2014) Did High-Speed Trains Promote the Development of Regional Economy? Shanghai Journal of Economics, 2, 82-91.

[24] Zhang, X.L. (2013) Has Transport Infrastructure Promoted Regional Economic Growth? With an Analysis of the Spatial Spillover Effects of Transport Infrastructure. Chinese Social Sciences (English Edition), 34, 24-47.

https://doi.org/10.1080/02529203.2013.787222 